\title{
Remoção de sulfato de efluentes industriais por precipitação
}

\author{
Sulfate removal from industrial effluents by precipitation
}

\author{
Bruno Christiano Silva Ferreira \\ Químico Industrial pela Universidade Federal de Ouro Preto (UFOP). Pós-graduando (Mestrado) do Programa de Pós-Graduação em Engenharia Ambiental \\ da UFOP

\section{Rosa Malena Fernandes Lima} \\ Engenheira de Minas pela UFOP. Doutora em Engenharia Metalúrgica e de Minas pela Universidade Federal de Minas Gerais (UFMG). Professora do \\ Departamento de Engenharia de Minas da UFOP. Coordenadora do Laboratório de Propriedades Interfaciais da UFOP
}

\section{Versiane Albis Leão}

Engenheiro Metalúrgico pela UFOP. Doutor em Engenharia Metalúrgica e de Minas pela UFMG. Professor do Departamento de Engenharia Metalúrgica e de Materiais da UFOP. Coordenador do Laboratório de Bio\&Hidrometalurgia da UFOP

\section{Resumo}

O objetivo deste trabalho foi estudar a remoção de íons sulfato, encontrados em efluentes de diversas atividades do setor mínero/metalúrgico. Os processos de remoção de sulfato desses efluentes são, em geral, caros e com baixa eficiência de remoção para essa espécie. Foram estudadas duas alternativas de tratamento para soluções ricas em sulfato. A primeira consistiu na investigação da remoção do íon em pH ácido, na forma de jarosita. Na segunda, foi estudada a remoção do sulfato como etringita, em pH alcalino. A etringita mostrou-se uma boa opção para o tratamento de efluentes líquidos contendo sulfato, pois apresentou baixa solubilidade em água em pH acima de 11,5. Em seguida, foi investigada a precipitação química de sulfato em soluções sintéticas contendo $1.500 \mathrm{mg} / \mathrm{L}$ do íon, em temperatura ambiente $\left(22 \pm 1^{\circ} \mathrm{C}\right)$, observando-se remoções próximas de $85 \%$ em sistemas contínuos de precipitação. Esses estudos mostram a redução dos teores finais de sulfato a valores inferiores a $250 \mathrm{mg} / \mathrm{L}$, ou seja, abaixo do que é recomendado pela legislação brasileira.

Palavras-chave: remoção de sulfato; drenagem ácida; etriginta; jarosita.

\section{Abstract}

The aim of this study was to develop alternative techniques for removing sulfate ions from mining/metallurgy effluents. Sulfate removal processes are generally expensive and show low removal efficiency. Two alternatives to treat sulfate-rich solutions were studied in this work. The first alternative was sulfate removal in acidic $\mathrm{pH}$, as jarosite. Moreover, the second precipitating alternative was tested in alkaline conditions, as ettringite. Sulfate removal as ettringite was considered the preferable form for treating sulfate-containing wastewaters due to its low solubility in water, close to $10 \mathrm{mg} / \mathrm{L}$ at the $\mathrm{pH}$ of 11.5 . Chemical precipitation of sulfate in synthetic solutions containing $1,500 \mathrm{mg} / \mathrm{L}$ sulfate, at the temperature of $22 \pm 1^{\circ} \mathrm{C}$, was thus investigated, and removals close to $85 \%$ in continuous precipitation systems were observed. This study showed sulfate reduction to final concentration values below $250 \mathrm{mg} / \mathrm{L}-$ lower than that recommended by environmental regulations.

Keywords: sulfate removal; acid mining drainage; ettringite; jarosite. 


\section{Introdução}

O ácido sulfúrico é o principal agente utilizado na lixiviação de minerais, no acabamento e polimento de superfícies, no processamento de minérios fosfatados, entre outros. Essas atividades geram um volume considerável de efluentes contendo sulfato. Outra atividade geradora de grandes volumes de efluentes contendo sulfato é a drenagem ácida de rocha (DAR) (INAP, 2003), que está associada à oxidação natural de minerais sulfetados contidos em rochas quando expostas à ação do ar e da água. Quando esse fenômeno está relacionado à atividade mineradora, o mesmo é chamado de drenagem ácida de mina (DAM). Em minerações, o ácido sulfúrico pode ser gerado, principalmente, pela oxidação da pirita $\left(\mathrm{FeS}_{2}\right)$ e da pirrotita $\left(\mathrm{FeS}_{1-\mathrm{x}}\right)$ (MOHAN e CHANDER, 2006). Grandes áreas de mineração produziram, durante décadas, um grande volume de DAM e, devido aos riscos ambientais vinculados a esse fenômeno, surgem pelo mundo propostas para a minimização desses efeitos deletérios (INAP, 2003)

Segundo a Organização Mundial da Saúde (WHO, 2008), o teor recomendável para a concentração de sulfato em água potável deve ser inferior a $500 \mathrm{mg} / \mathrm{L}$. Já a United States Environmental Protection Agency (USEPA) determina um teor inferior a 250 mg/L (USEPA, 2009). Assim, muitos países recomendam uma faixa entre 250 a $500 \mathrm{mg} / \mathrm{L}$ de sulfato como limite máximo em efluentes e em águas para diversos usos, humanos e animais (INAP, 2003).

Estudos recentes usam quatro abordagens para a remoção de sulfato desses efluentes (INAP, 2003): (i) tratamento químico envolvendo precipitação; (ii) processos que utilizam membranas ou (iii) troca iônica e (iv) redução biológica de sulfato. Esses processos de tratamento de efluentes que contêm sulfato foram documentados e alguns testados em planta piloto (INAP, 2003), porém, nem todos são economicamente atrativos, a não ser que a água possa ser comercializada. $O$ estudo de um agente precipitante para o íon sulfato, de baixo custo, pode ser uma alternativa para tratar esses efluentes. Como os efluentes gerados pela mineração têm teor variável de sulfato, o desafio está justamente em encontrar um método eficaz e barato para esta aplicação.

$\mathrm{O}$ uso de $\mathrm{Ca}(\mathrm{OH})_{2}$ e $\mathrm{CaCO}_{3}$ como agentes precipitantes de íons sulfato é aplicado em larga escala no Brasil. Porém, a eficiência do processo é limitada a uma faixa de concentração consideravelmente alta, ou seja, superior a $1.200 \mathrm{mg} / \mathrm{L}$ de $\mathrm{SO}_{4}{ }_{4}^{2-}$ (GELDENHUYs et al., 2003). Dessa forma, o uso desses agentes precipitantes fica comprometido, dificultando o enquadramento dos efluentes aos valores definidos pelas legislações ambientais vigentes pelo mundo. A utilização de sais de bário e chumbo, para precipitação desses metais como sulfatos, tem sido investigada, uma vez que esses produtos apresentam uma baixa solubilidade, porém, tais processos ainda não são considerados economicamente atraentes. Trata-se de uma alternativa, principalmente se aplicada ao tratamento de efluentes com concentração moderada do íon. Nesse caso, os custos para separação e disposição apropriada dos precipitados gerados, bem como a toxidade dos resíduos, deverão ser observados (SILVA et al., 2002).
Para o enquadramento e o descarte dos efluentes que contenham sulfato, de acordo com a legislação vigente, busca-se a utilização de outros precipitantes que consigam reduzir os teores de sulfato à concentrações menores que as obtidas pela adição de cal, aliando essa redução à disposição adequada dos sólidos gerados. O sulfato, quando em contato com cátions $\mathrm{Fe}^{3+}$ e outro cátion metálico de carga +1 , em condições físico-químicas adequadas, leva à formação de jarosita, um mineral de fórmula estrutural $\left(\left(\mathrm{Me}^{+}\right)_{2} \mathrm{Fe}_{6}(\mathrm{OH})_{12}\left(\mathrm{SO}_{4}\right)_{4}\right)$ na qual $\mathrm{Me}^{+}$representa um cátion metálico de carga +1 (TAVARES, 1986). Outro caminho é a formação da etringita $\left(\mathrm{Ca}_{6} \mathrm{Al}_{2}\left(\mathrm{SO}_{4}\right)_{3}(\mathrm{OH})_{12} \cdot 26 \mathrm{H}_{2} \mathrm{O}\right)$, quando o sistema contaminado com sulfato é posto em contato com cátions de $\mathrm{Al}^{3+} \mathrm{e} \mathrm{Ca}^{3+}$, em condições de pH alcalino (CADORIN, 2008). Essas rotas têm sido estudadas pelo baixo custo do tratamento e também pela eficiência na remoção do sulfato.

Especificamente, este trabalho teve como objetivo estudar a remoção de íons sulfato de soluções sintéticas e de efluentes industriais, por meio de técnicas de precipitação de fases mineralógicas, como a etringita e a jarosita. Visou também estudar os efeitos da concentração dos reagentes, da temperatura, e do $\mathrm{pH}$ do meio na precipitação de jarosita e de etringita e, consequentemente, no grau de remoção de sulfato presente no sistema. Finalmente, foram realizados ensaios em sistemas contínuos para o processo que apresentar melhores resultados.

\section{Materiais e métodos}

\section{Precipitação de jarosita}

Os ensaios em batelada de precipitação de jarosita foram realizados, em duplicada, com efluente sintético, produzido a partir do sal sulfato de sódio, em concentrações de 1.500 mg/L de sulfato. Foram adicionados, em erlenmeyers de $250 \mathrm{~mL}, 100 \mathrm{~mL}$ de solução sintética de sulfato de sódio e os sais cloreto de ferro III $\left(\mathrm{FeCl}_{3}\right)$ e cloreto de amônio $\left(\mathrm{NH}_{4} \mathrm{Cl}\right)$, em condições controladas de $\mathrm{pH}$. A adição dos cátions, ferro (III) e amônio foi feita respeitando a razão molar $\mathrm{SO}_{4}^{2-}: \mathrm{NH}_{4}^{+}: \mathrm{Fe}^{3+}$ de 2:1,0:3,0, ou seja, para 0,016 mol/L de $\mathrm{SO}_{4}^{2-}$ foram adicionados $0,008 \mathrm{~mol} / \mathrm{L}$ de $\mathrm{NH}_{4}^{+}$e $0,024 \mathrm{~mol} / \mathrm{L}$ de $\mathrm{Fe}^{3+}$. A utilização dessa proporção molar foi proposta por Tavares (1986), em seu estudo de precipitação de jarosita em soluções saturadas de sulfato de manganês. Também foi adicionado $0,15 \mathrm{~g}$ de jarosita de amônio ao elernmeyer, com a finalidade de que os cristais introduzidos servissem como semente de precipitação (nucleação secundária), diminuindo as barreiras energéticas de formação de novos cristais. $\mathrm{O}$ pH do sistema foi controlado com o auxílio de soluções de $\mathrm{HCl}(0,1 \mathrm{M})$ e $\mathrm{NaOH}(0,1 \mathrm{M})$, durante as seis primeiras horas de experimento e também nas seis últimas horas, garantindo, assim, uma variação de $\pm 0,1$ do valor de $\mathrm{pH}$ previamente fixado. Os sistemas permaneceram sob agitação (150 mim-1), em shaker termostatizado, durante 24 horas. Para a separação dos sólidos gerados nos ensaios de precipitação, usou-se a filtração, à vácuo, da polpa. Em seguida, a fase sólida foi lavada com água destilada e etanol e seca em 
estufa, a $50^{\circ} \mathrm{C}$, durante 24 horas. Os licores foram acidificados com $\mathrm{HNO}_{3}$ (ácido nítrico) e enviados para análise química em espectrofotômetro de emissão atômica com fonte de plasma (ICP-OES). Foram estudados os efeitos do $\mathrm{pH}$ (variado de 1,0 até pH 3,0) e da temperatura (de $70^{\circ} \mathrm{C}$ a $90^{\circ} \mathrm{C}$ ) sobre a formação da fase jarosita.

\section{Precipitação de etringita}

Foram adicionados a $100 \mathrm{~mL}$ de solução sintética de sulfato $(1.500 \mathrm{mg} / \mathrm{L}), \mathrm{Ca}(\mathrm{OH})_{2}$ e $\mathrm{Al}(\mathrm{OH})_{3}$, respeitando a razão molar $\mathrm{SO}_{4}{ }^{2--}: \mathrm{Ca}^{2+}: \mathrm{Al}^{3+}$ igual a 1,0:2:0,67, ou seja, 0,016 mol/L de sulfato, 0,031 mol/L de cálcio e 0,01 mol/L de alumínio. Foram utilizadas condições controladas de $\mathrm{pH}$, que foi ajustado com soluções de $\mathrm{HCl}$ $(0,1 \mathrm{M})$ e $\mathrm{NaOH}(0,1 \mathrm{M})$, garantindo assim uma variação de $\pm 0,2$ do valor previamente fixado. Os experimentos foram conduzidos, em duplicada, em erlenmeyers de $250 \mathrm{~mL}$ e manteve-se o sistema em agitação $\left(150 \mathrm{mim}^{-1}\right)$, em shaker termostatizado, durante 24 horas. Ao término do ensaio, a solução foi filtrada e os sólidos gerados foram encaminhados para caracterização. Os licores foram acidificados com $\mathrm{HNO}_{3}$ e encaminhados para análise em ICP-EOS. Foram estudados o efeito do $\mathrm{pH}$ (entre de 7,0 e 14,0); da temperatura $\left(25,35,60\right.$ e $70^{\circ} \mathrm{C}$ ) e da razão molares entre os precipitantes (para concentração fixa de sulfato em 0,016 mol/L, a concentração de $\mathrm{Al}^{3+}$ foi variada entre 0,04 e 0,026 mol/L e a de $\mathrm{Ca}^{2+}$, entre 0,015 mol/L e 0,078 mol/L).

\section{Estudos em contínuo}

Os estudos em sistema contínuo para a remoção de sulfato foram realizados, em duplicata, aplicando-se as melhores condições encontradas em sistemas em batelada para o tratamento de solução sintética de sulfato e precipitação de etringita. Foram definidas: (i) temperatura de $22 \pm 1^{\circ} \mathrm{C}$; (ii) $\mathrm{pH}$ na faixa de 10,2 a 12 ; (iii) tempos de residência no reator igual a 30 minutos. Foi preparada uma solução sintética de sulfato (1.500 mg/L) e alumínio (720 mg/L), obtidos a partir do hidróxido de alumínio e ácido sulfúrico/sulfato de sódio, em pH 3,2. Preparou-se também polpa de hidróxido de cálcio (leite de cal), com concentração total de cálcio igual a $1.200 \mathrm{mg} / \mathrm{L}$. Essas soluções foram alimentadas com o auxílio de bombas peristálticas (Milan, modelo 628) a um reator (600 mL de volume útil) munido de agitação magnética. O pH foi aferido constantemente com o auxílio de um pHmetro portátil Hanna instruments, modelo HI - 9622, e a agitação do reator foi feita com o auxílio de um agitador magnético $\left(240 \mathrm{~min}^{-1}\right)$. Amostras da polpa eram recolhidas periodicamente na frequência de 30 minutos e filtradas. A solução era acidificada com $\mathrm{HNO}_{3}$ e analisada em um espectrômetro de emissão atômica com fonte de plasma, Spectro, modelo Cirus CCD, para determinação do teor de sulfato final do sistema. O sólido obtido na filtração era enviado para caracterização por difração de raios X, equipamento de microscopia eletrônica de varredura-sistema de energia dispersiva (MEV-EDS e distribuição granulométrica.

\section{Caracterização dos precipitados}

A distribuição de tamanho de cristais foi obtida no equipamento CILAS 1064, do Laboratório de Propriedades Interfaciais do Departamento Engenharia de Minas da Universidade Federal de Ouro Preto (UFOP). A morfologia das amostras foi analisada em um equipamento de microscopia eletrônica de varredura e EDS modelo JEOL JSM5510. O mapeamento dos elementos presentes nos precipitados foi feito utilizando-se um equipamento de MEV e EDS modelo JEOL JSM-5510 (análise química semiquantitativa pontual, sistema de micro análise EDS da marca Thermo Electron modelo System Six. As amostras foram prensadas para tornar a superfície perfeitamente plana, e mm de tornar a superfície condutora. As análises foram feitas usando uma ddp de $20 \mathrm{kV}$ para o filamento capilar de tungstênio.

\section{Resultados e discussão}

\section{Remoção de íons sulfato em meio ácido - precipitação de jarosita}

De acordo com os resultados apresentados na Figura 1, observa-se que o maior percentual de remoção de sulfato (próximo de 40\%) está na faixa de $\mathrm{pH}$ de 1,5 a 2, que se enquadra nos dados da literatura e é característica para a formação da jarosita (TAVARES, 1986), ou seja, há uma maior remoção do íon sulfato presente no efluente sintético, nessa região. Entretanto, o teor residual de sulfato ainda é elevado, próximo de 875 mg/L, o que não atende a normatização ambiental brasileira e os valores definidos como padrão neste trabalho (250 mg/L).

Dutrizac (1996) estudou os vários equilíbrios iônicos que ocorrem em sistemas sulfúricos que contêm cátions metálicos. Tais estudos indicam que a concentração das diferentes espécies iônicas de ferro dependem fortemente do $\mathrm{pH}$ da solução. Nesses sistemas, foi detectada

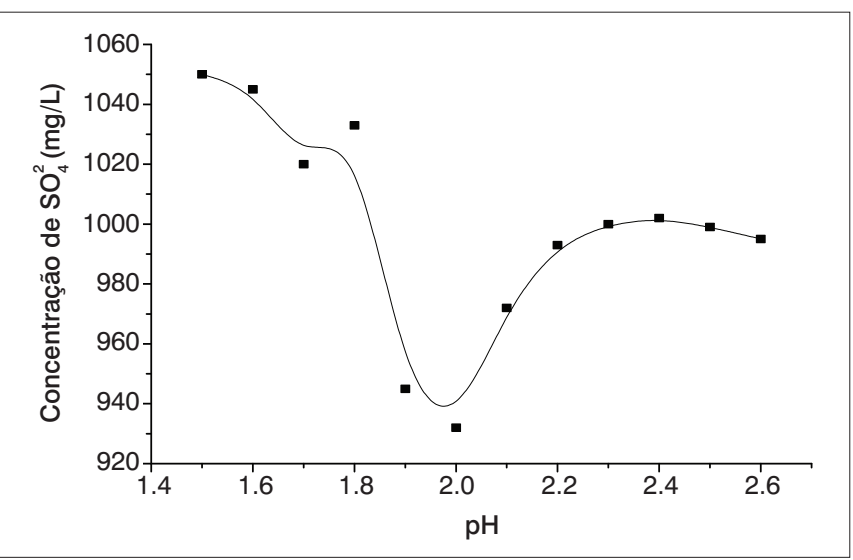

Figura 1 - Concentração residual de sulfato em função do pH durante a precipitação de jarosita. Concentração inicial de $1.500 \mathrm{mg} / \mathrm{L}$ de sulfato, tempo de reação de 24 horas e temperatura de $70^{\circ} \mathrm{C}$. Para cada $0,016 \mathrm{~mol} / \mathrm{L}$ de $\mathrm{SO}_{4}{ }_{4}^{2-}$ adicionaram-se $0,008 \mathrm{~mol} / \mathrm{L}$ de amônio e $0,024 \mathrm{~mol} / \mathrm{L}$ de ferro (III) e também $0,15 \mathrm{~g}$ de jarosita de amônio (semente). 
a precipitação de $\mathrm{Fe}(\mathrm{III})$ sobre a forma de hidróxido $\left(\mathrm{Fe}(\mathrm{OH})_{3}\right)$, óxido de ferro $\left(\mathrm{Fe}_{2} \mathrm{O}_{3}\right.$ ), goethita $(\mathrm{FeOOH})$ e jarosita. Segundo o autor, a taxa de precipitação da jarosita depende principalmente: da temperatura, da relação entre as concentrações das espécies catiônicas, do pH, da concentração de ferro e de sulfato em solução.

Limpo et al. (1976) estudaram a influência da acidez, da concentração de Fe(III), da concentração de amônio e da adição de cristais (sementes) sobre a taxa de precipitação de Fe(III) como jarosita de amônio, em soluções sulfúricas, na faixa de temperaturas de $90^{\circ} \mathrm{C}$ a $100^{\circ} \mathrm{C}$. A etapa controladora do processo foi o crescimento de cristais e, para esses estudos, a taxa de nucleação foi proporcional à superfície introduzida no sistema, à concentração de amônia e à concentração do hidroxicomplexo $\mathrm{Fe}_{2}(\mathrm{OH})_{4}{ }^{2+}$ - produzido no sistema, que é inversamente proporcional à acidez da solução. Com este estudo, verificou-se que a acidez da solução exerce uma importante influência sobre a taxa de precipitação, pois os íons hidrogênio são adsorvidos na superfície da jarosita, competitivamente com íons amônio. Além disso, o pH regula a concentração do complexo $\mathrm{Fe}_{2}(\mathrm{OH})_{4}{ }^{2+}$, espécie fundamental para a formação dos cristais de jarosita. Nos experimentos realizados neste trabalho, conclui-se que o controle do pH é um dos meios de garantir o sucesso da precipitação dessa espécie.

A Tabela 1 apresenta os valores de remoção de sulfato, durante os experimentos que avaliaram a influência da temperatura na precipitação de jarosita.

Segundo Tavares (1986), o aumento da temperatura favorece a formação da fase mineralógica em estudo. Para razões molares estequiométricas das espécies envolvidas no processo de precipitação e pH igual a 2, a variação da temperatura $\left(80,85\right.$ e $\left.90^{\circ} \mathrm{C}\right)$ não mostrou resultados consideravelmente diferentes daqueles encontrados a $70^{\circ} \mathrm{C}$, o que mostra uma baixa influência das temperaturas estudas na remoção do sulfato. Ainda segundo Tavares (1986), temperaturas superiores a $100^{\circ} \mathrm{C}$ favorecem a cinética de formação de jarosita, porém, essa temperatura inviabiliza o tratamento dos efluentes.

Resultados experimentais obtidos em sistemas de biolixiviação, ricos em sulfato, estudados por Toro (1988), sugerem a formação de jarosita a uma temperatura de $30^{\circ} \mathrm{C}$ em meios ricos na bactéria Acidithiobacillus. A precipitação de jarosita, nesses sistemas, tem uma cinética muito favorável e pouca seletividade quanto ao $\mathrm{pH}$ e isso se deve às altas concentrações de ferro (III), às condições favoráveis para a formação de intermediários da precipitação dessa fase e também à presença de células bacterianas que servem de superfícies de crescimento de cristais.

A caracterização do precipitado foi feita por DRX e MEV-EDS. Os difratogramas obtidos para o precipitado indicaram a formação de jarosita de amônio pura. Para pH inferior a 2, observou-se o aparecimento de picos indicativos da presença de hidroniojarosita, o que é pertinente, pois se observa uma maior competitividade entre os cátions amônio e hidrônio nessa região, graças ao aumento da concentração de $\mathrm{H}^{+}$no meio reacional, o que é similar ao relatado por Dutrizac (1996). Os difratogramas apresentados mostraram também uma alta cristalinidade do sólido formado, graças à presença de picos bem definidos (FERREIRA, 2010).

A morfologia dos cristais de jarosita, obtidos nos ensaios conduzidos a $85^{\circ} \mathrm{C}$ e pH igual a 2 , corresponde a agregados esféricos constituído por cristais romboédricos em uma estrutura compacta, como mostrado na Figura 2, de acordo com o que foi relatado no caso da hidroniojarosita e da jarosita amônio (Raman et al., 1998). Os

Tabela 1 - Remoção de sulfato, como jarosita, em função da temperatura. Concentração inicial de sulfato igual a 1.480 mg/L, pH 2, $150 \mathrm{~min}^{-1}$

\begin{tabular}{cccccc} 
Temperatura $\left({ }^{\circ} \mathrm{C}\right)$ & {$\left[\mathrm{SO}_{4}{ }^{2-}\right]_{\text {inicial }}(\mathrm{mol} / \mathrm{L})$} & {$\left[\mathrm{NH}_{4}{ }^{+}\right]_{\text {inicial }}(\mathrm{mol} / \mathrm{L})$} & {$\left[\mathrm{Fe}^{3+}\right]_{\text {inicial }}(\mathrm{mol} / \mathrm{L})$} & {$\left[\mathrm{SO}_{4}{ }^{2-}\right]_{\text {final }}$ (mg/L) } & Remoção de sulfato $(\%)$ \\
\hline 80 & 0,016 & 0,008 & 0,023 & 843 & 43,04 \\
85 & 0,016 & 0,008 & 0,023 & 846 & 43,85 \\
\hline 90 & 0,016 & 0,008 & 0,023 & 829 & 43,98 \\
\hline
\end{tabular}
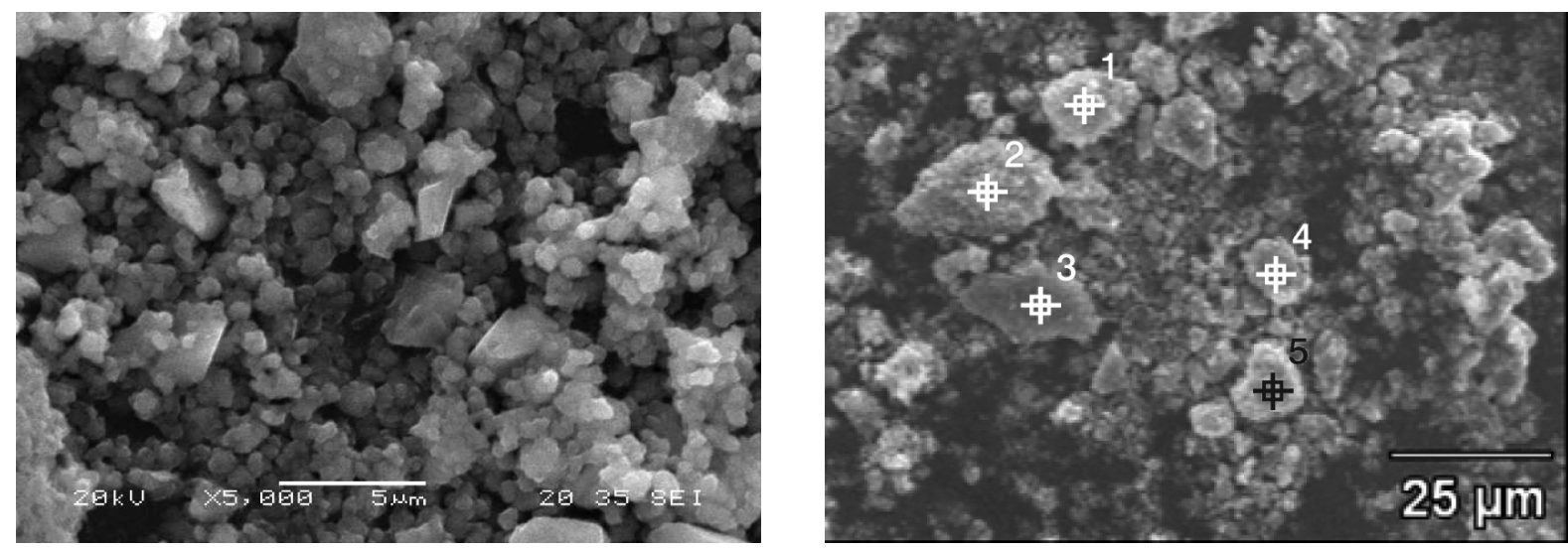

Figura 2 - Imagens para a jarosita precipitada. (A) Cristais; (B) pontos selecionados para análise de EDS. Condições experimentais: concentração estequiométrica de ferro (III), amônio e sulfato, agitação $240 \mathrm{~min}^{-1}, 24$ horas de ensaio, $85^{\circ} \mathrm{C}$ e pH igual a 2. 
pontos mostrados na Figura 2B foram selecionados para análise de EDS (Tabela 2), que apresenta a composição encontrada durante as análises de EDS e a composição esperada para jarosita de amônio. Comparando os valores obtidos, observa-se uma similaridade muito grande entre os valore teóricos e os valores obtidos para a jarosita de amônio.

Observa-se, na prática, que essa alternativa de tratamento de soluções ricas com sulfato em meio ácido é pouco efetiva, pois, para as condições experimentais abordadas neste trabalho, a remoção de íons sulfato não é satisfatória, produzindo concentrações finais do ânion acima de $800 \mathrm{mg} / \mathrm{L}$.

\section{Remoção de íons sulfato em meio alcalino - precipitação de etringita}

A remoção de íons sulfato via formação de etringita, a $35^{\circ} \mathrm{C}$, foi estudada inicialmente em batelada. Observa-se, pelos resultados apresentados na Figura 3, uma redução no teor residual de sulfato na faixa de pH 10,5 a 13,0, zona característica de estabilidade da etringita. Assim, a redução do teor de sulfato (1.480 mg/L iniciais) ultrapassa índices de 90\%, na presença de cálcio e alumínio, cujas concentrações correspondem aos valores estequiométricos, ou seja, para cada 1,0 mol de $\mathrm{SO}_{4}{ }^{2-}$, tem-se 0,67 mol de $\mathrm{Al}^{3+}$ e 2 mol de $\mathrm{Ca}^{2+}$. Myneni et al. (1998) relataram que a etringita ainda pode ser estável em pH 9,5, em meios contendo gesso e hidróxido de alumínio. No entanto, é mais amplamente divulgado que as condições favoráveis de pH para formação da etringita estão entre 11 e 12,5 (Cadorin, 2008). A redução da concentração de sulfato nesses sistemas é praticamente a mesma, ficando próxima a 92\%, o que gera licores com concentrações finais de sulfato próximas a $120 \mathrm{mg} / \mathrm{L}$.

A Tabela 3 mostra os resultados obtidos quando foi variada a temperatura de precipitação da etringita na faixa de pH entre 11,0 e 12,0. Este estudo mostra que os melhores resultados de remoção do íon, via a precipitação de etringita, foram obtidos para $\mathrm{pH}$ 11,5 e que a temperatura não tem efeito significativo na remoção de sulfato.

Pode-se perceber, a partir da Tabela 3, que, em todas as temperaturas e valores de $\mathrm{pH}$, a concentração de sulfato foi reduzida a valores inferiores a $250 \mathrm{mg} / \mathrm{L}$. Desse modo, o pH e a temperatura não exercem efeito significativo sobre a remoção de sulfato, nas condições estudadas, já que os valores de remoção ficam em torno de 93 a 94\%. Observa-se, nestes sistemas, a formação de cristais com o diâmetro a $50 \%$, ou seja, $\mathrm{d}_{50}$ próximos de $15 \mu \mathrm{m}$ para todas as temperaturas e $\mathrm{pH}$ estudados, evidenciando, assim, a pouca influência da temperatura e de $\mathrm{pH}$ na distribuição do tamanho dos cristais de etringita gerados.

A influência da concentração dos reagentes na remoção de sulfato é mostrada na Figura 4 para a temperatura de $35^{\circ} \mathrm{C}$.

Os resultados destes experimentos mostram concentrações residuais de sulfato inferiores a $100 \mathrm{mg} / \mathrm{L}$, em quaisquer concentrações dos cátions metálicos acima dos valores estequiométricos, ou seja, para a relação molar $\mathrm{SO}_{4}^{2-}: \mathrm{Ca}^{2+}: \mathrm{Al}^{3+}$ igual a 1,0:2:0,67, o que não acontece quando se disponibilizam os reagentes em concentrações inferiores às estequiométricas. Estes resultados mostram valores satisfatórios de remoção de sulfato, quando comparados aos resultados relatados na literatura. De acordo com Laubscher et al., (2003) e Cadorin (2008), o intervalo de pH ideal para formação da etringita é de 11,4 a 12,4. Segundo Cadorin (2008), a máxima remoção de sulfato (98\% de remoção para $1700 \mathrm{mg} / \mathrm{L}$ de sulfato) foi alcançada em pH 12, para concentrações dos íons alumínio e cálcio equivalentes à uma e duas vezes, respectivamente

Tabela 2 - Proporção em peso, obtida por EDS, dos elementos químicos presentes nos precipitados de jarosita (Figura 2B)

\begin{tabular}{|ccccc|}
\hline Ponto & Oxigênio & Nitrogênio & Enxofre & Ferro \\
\hline 1 & 44,35 & 2,21 & 15,54 & 37,90 \\
\hline 2 & 46,25 & 2,46 & 14,65 & 36,64 \\
\hline 3 & 45,02 & 3,20 & 13,74 & 38,04 \\
\hline 4 & 47,70 & 2,97 & 13,62 & 35,70 \\
\hline 5 & 45,71 & 3,75 & 15,27 & 35,38 \\
\hline $\begin{array}{c}\text { Jarosita de amônio } \\
\text { (teórico) }\end{array}$ & 47,71 & 2,98 & 13,63 & 35,68 \\
\hline
\end{tabular}

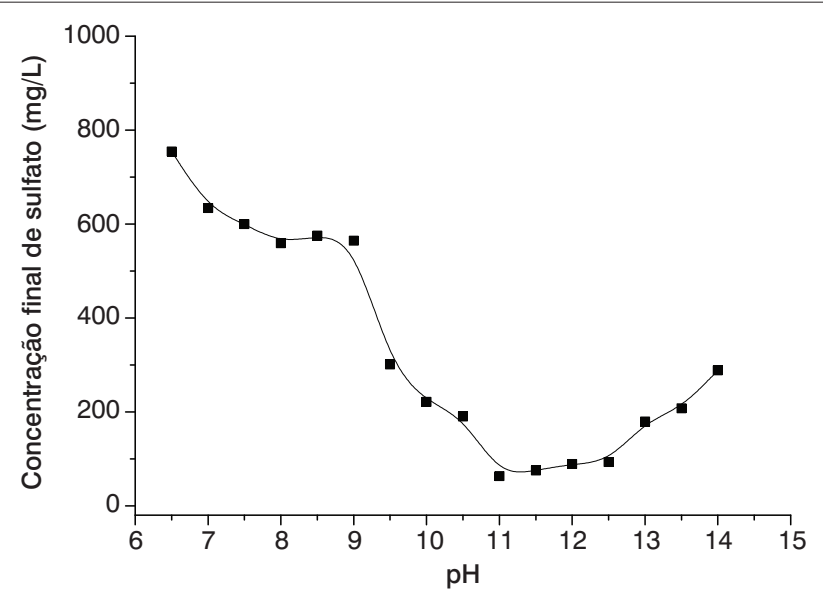

Figura 3 - Concentração residual de sulfato, no tratamento em batelada com concentração inicial do íon de $1.480 \mathrm{mg} / \mathrm{L}$, agitação de $240 \mathrm{~min}^{-1}$, concentrações estequiométricas de cálcio e alumínio e temperatura de $35^{\circ} \mathrm{C}$.

Tabela 3 - Remoção de sulfato em batelada via precipitação de etringita, em função da temperatura e proporção estequiométrica entre os reagentes, concentração inicial de sulfato igual a $1.480 \mathrm{mg} / \mathrm{L}$ e agitação de 240 min $^{-1}$

\begin{tabular}{cccccc}
$\begin{array}{c}\text { Temperatura } \\
\left({ }^{\circ} \mathrm{C}\right)\end{array}$ & $\begin{array}{c}\mathrm{pH} \\
\text { inicial }\end{array}$ & $\begin{array}{c}\mathrm{pH} \\
\text { final }\end{array}$ & $\begin{array}{c}\text { Teor final de } \\
\text { sulfato }(\mathrm{mg} / \mathrm{L})\end{array}$ & $\begin{array}{c}\text { Remoção } \\
(\%)\end{array}$ & $\begin{array}{c}\text { Diâmetro a } \\
50 \%(\mu \mathrm{m})\end{array}$ \\
\hline 22 & 11,0 & 10,9 & 139 & 90.6 & 14,4 \\
\hline 22 & 11,5 & 11,5 & 119 & 91,9 & 15,3 \\
\hline 22 & 12,0 & 11,9 & 124 & 91,6 & 14,9 \\
\hline 35 & 11,0 & 11,0 & 136 & 90,8 & 15,5 \\
\hline 35 & 11,5 & 11,4 & 121 & 91,8 & 13,9 \\
\hline 35 & 12,0 & 12,1 & 129 & 91,3 & 14,3 \\
\hline 60 & 11,0 & 11,0 & 102 & 93,1 & 13,9 \\
60 & 11,5 & 11,6 & 85,3 & 94,2 & 14,4 \\
\hline 60 & 12,0 & 12,1 & 99,6 & 93,3 & 15,8 \\
70 & 11,0 & 11,1 & 112 & 92,4 & 14,3 \\
70 & 11,5 & 11,6 & 109 & 92,6 & 14,7 \\
70 & 12,0 & 12,1 & 115 & 92,2 & 15,1 \\
\hline
\end{tabular}


aos valores estequiométricos para formação da etringita, valores superiores ao observado no presente trabalho.

A análise da difração de raios $\mathrm{X}$ dos precipitados indicou a formação de etringita como fase pura nas condições experimentais estudadas (FERREIRA, 2010). Os cristais de etringita formam agregados constituídos por cristais aciculares, compostos de prismas ou cilindros (ALVAREZ-AYUZO et al., 2005; CODY et al., 2004), como mostra a Figura 5A. Na Figura 5B são apresentados os pontos selecionados para a análise de EDS para o sólido gerado durante precipitação do sulfato, na temperatura de $35^{\circ} \mathrm{C}$ e pH de 11,5 . A Tabela 4 mostra a composição encontrada durante as análises de EDS e a composição teórica da espécie identificada pelo DRX. Nos pontos de 1 a 7 , identifica-se a etringita, já que há uma grande similaridade entre os valores teóricos para essa espécie e os encontrados na análise.

\section{Remoção de íons sulfato em ensaios contínuos - precipitação de etringita}

Os ensaios em sistema contínuo foram realizados em um reator do tipo Mixed Suspension Mixed Product Removal (MSMPR). Dentre os estudos em contínuo para a remoção do íon sulfato foram realizados ensaios com e sem controle do pH. Esses ensaios de síntese de etringita foram efetuados com a utilização de solução sintética de sulfato de sódio (1.654 mg/L), em condições de temperatura ambiente e concentrações estequiométricas dos agentes precipitantes. Tais ensaios visaram à redução dos teores de sulfato no efluente sintético para valores inferiores a $250 \mathrm{mg} / \mathrm{L}$, padrão adotado pela resolução 357/05 do Conselho Nacional do Meio Ambiente (CONAMA). A Figura 6 apresenta os resultados da variação da concentração de sulfato, alumínio nos experimentos com controle (A) e sem controle do $\mathrm{pH}$ (B).

Nos ensaios com controle do pH (Figura 6A), este foi mantido no valor de 11,6 e, naquele sem controle do $\mathrm{pH}$, o mesmo variou entre
11,3 e -11,8. Observa-se que os experimentos de remoção de sulfato foram eficientes, independentemente do controle ou não do $\mathrm{pH}$, atingindo valores próximos a $230 \mathrm{mg} / \mathrm{L}$, no efluente final. Sendo assim, o que deve ser avaliado nesses tratamentos são as condições experimentais, tais como tempo em que o sistema proposto atinge o regime e a necessidade ou não da adição de hidróxido de sódio. Os resultados mostram que o regime em ambos os casos é alcançado em seis tempos de residência, porém o experimento realizado sem a presença

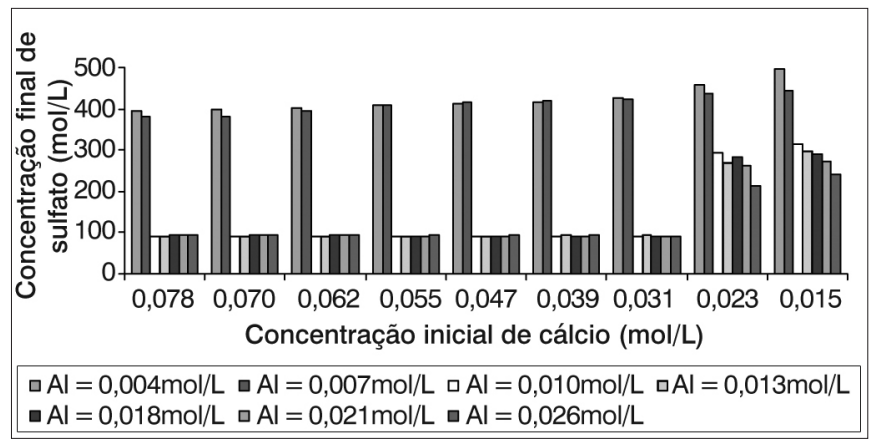

Figura 4 - Remoção de sulfato em função das concentrações de $\mathrm{Ca}^{2+} \mathrm{e}$ $\mathrm{Al}^{3+}$, a $35^{\circ} \mathrm{C}, \mathrm{pH} 11,5$, concentração inicial de sulfato $1.480 \mathrm{mg} / \mathrm{L}$, ensaio em batelada e agitação igual a $240 \mathrm{~min}^{-1}$.

Tabela 4 - Porcentagem em peso das espécies presentes nas partículas apresentadas na Figura 5B

\begin{tabular}{|ccccc|}
\hline Ponto & Oxigênio & Alumínio & Cálcio & Enxofre \\
\hline 1 & 65,00 & 3,27 & 18,76 & 8,27 \\
\hline 2 & 43,50 & 6,45 & 25,56 & 9,56 \\
\hline 3 & 63,10 & 4,97 & 17,78 & 8,50 \\
\hline 4 & 66,88 & 5,27 & 18,84 & 9,01 \\
\hline 5 & 68,21 & 3,43 & 19,69 & 8,68 \\
\hline 6 & 61,34 & 4,68 & 20,13 & 8,80 \\
\hline 7 & 65,47 & 4,46 & 19,55 & 8,83 \\
\hline Etringita & 66,74 & 4,60 & 20,49 & 8,17 \\
\hline (teórico) & & & & \\
\hline
\end{tabular}

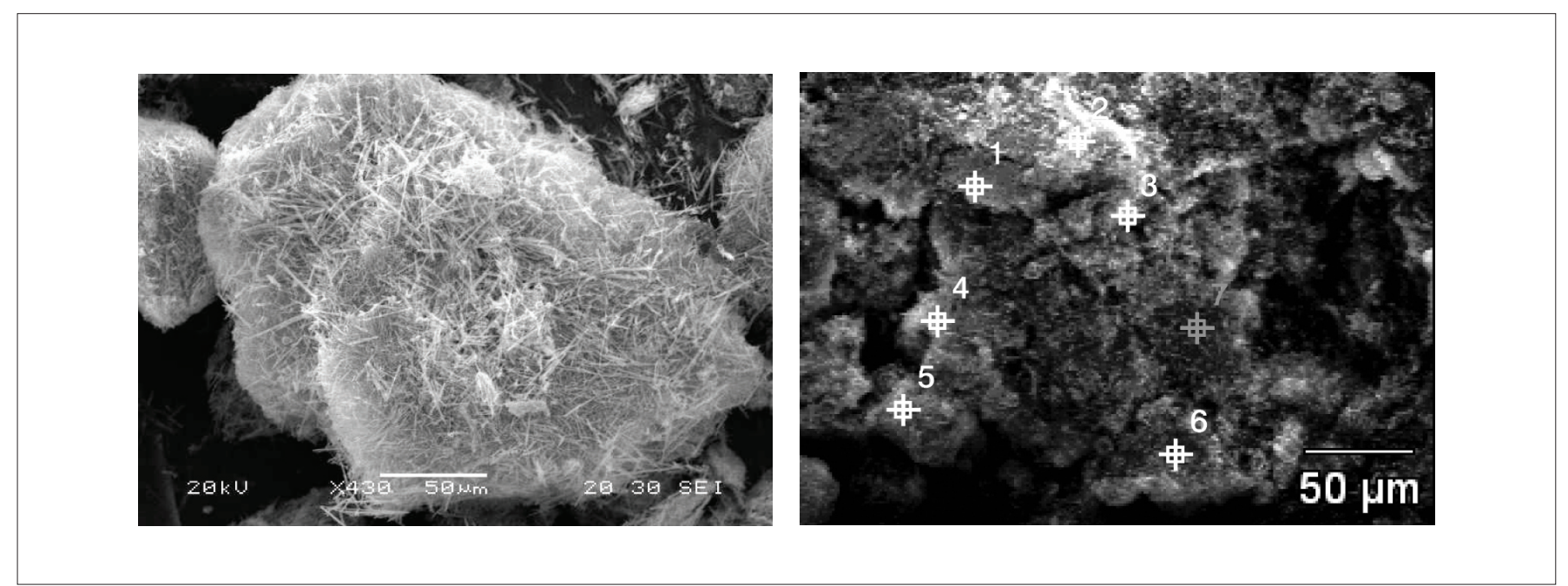

Figura 5 - Etringita precipitada na temperatura de $35^{\circ} \mathrm{C}$, relação estequiométrica entre cálcio, alumínio e sulfato e pH de 11,5. (A) Cristais; (B) pontos selecionados para análise de MEV-EDS. 


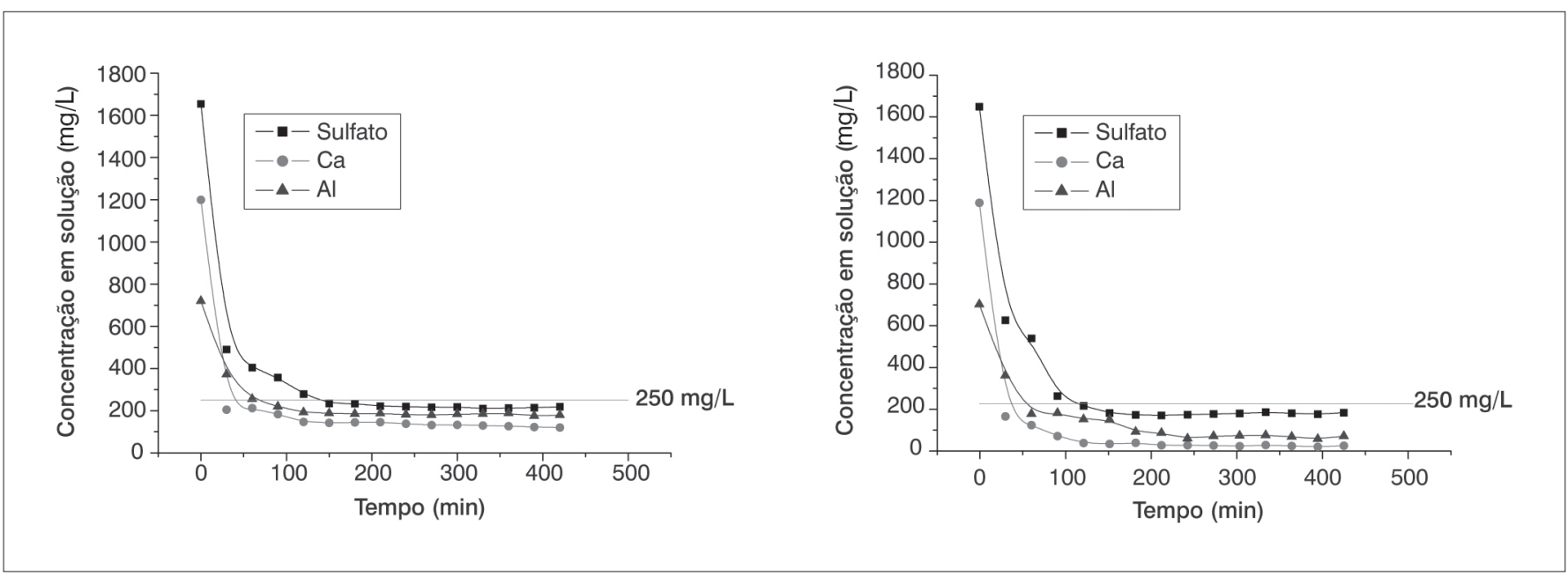

Figura 6 - Variação das concentrações sulfato, alumínio e cálcio em (mg/L) durante a precipitação de entrigita em sistema contínuo, com (A) e sem controle (B) do pH. Tempo de residência de 30 minutos, agitação de $240 \mathrm{~min}^{-1}$, temperatura ambiente $\left(22 \pm 1^{\circ} \mathrm{C}\right)$.

de hidróxido de sódio indica menores custos com insumos químicos para uma estação de tratamento de efluentes contaminados por sulfato. Cadorin (2008), em seus experimentos de precipitação de etringita, observou que o tempo de 40 minutos era suficiente para a remoção do sulfato em águas de mina e em soluções sintéticas quando se disponibilizam as concentrações de íons alumínio e cálcio equivalentes a uma e duas vezes aos valores estequiométricos, respectivamente. A discordância entre os estudos feitos por Cadorin (2008) e os obtidos pelos autores deste trabalho pode ser explicada pelo tipo de reagente e tratamento utilizados durante ambos os estudos. Vale salientar que os estudos descritos por Cadorin (2008) se baseiam na adição de policloreto de alumínio (PAC) e Alupan ${ }^{\circledR}$ em uma usina piloto de tratamento de efluentes. Essa autora mostra ainda em seu trabalho que, com o aumento da disponibilização desses reagentes em relação ao sulfato, obtém-se uma diminuição considerável do tempo necessário para que o sistema proposto entre em regime. Nessa situação, Cadorin (2008) recomenda o uso de Alupan $^{\circledR}$, pois esse sal não possui cloreto o que evita a formação de espécies como a hidrocalumita e não compromete a qualidade do efluente após o tratamento de precipitação.

Foram analisados os precipitados provenientes do reator MSMPR, a partir do momento em que o mesmo entrou em regime. O padrão dos difratogramas de raios X (DRX) indicou a presença de picos basais repetidos, que confirmam o material como uma espécie lamelar (VIEIRA, 2009). O material sintetizado em todos os ensaios possui uma boa cristalinidade e pureza de fase (etringita), indicados pela altura e largura a meia altura dos picos. A caracterização do precipitado via MEV, juntamente da análise de EDS, confirmou a presença de cristais de etringita, com aspecto acicular, aglomerados entre si (FERREIRA, 2010). A análise granulométrica mostrou valores do $\mathrm{d}_{50}$ iguais nas $8,5 \mu \mathrm{m}$ (com controle do $\mathrm{pH}$ ) e 7,2 $\mu \mathrm{m}$ (sem controle do $\mathrm{pH}$ ), confirmando o não efeito do controle do pH sobre a remoção de sulfato como etringita.
A remoção de sulfato como etringita em sistema contínuo pode ser uma alternativa à remoção de sulfato com cal, prática largamente adotada no país, uma vez que íons cálcio estão normalmente presentes nos efluentes da indústria mineral. A adição conjunto de sais de alumínio e cálcio irá garantir uma melhor remoção do ânion e seu enquadramento à legislação ambiental brasileira.

\section{Conclusões}

Os estudos realizados mostram que a remoção de íons sulfato está diretamente ligada ao pH. A alternativa de remoção dessa espécie em meio ácido fica comprometida, devido à cinética desfavorável de precipitação da jarosita nas condições de temperaturas estudadas. Já a precipitação de sulfato via a formação de etringita, apresenta valores de remoção satisfatórios, gerando, em batelada, licores com concentrações finais do íon próximas de $100 \mathrm{mg} / \mathrm{L}$, valor este que atende ao padrão determinado pela legislação ambiental brasileira, para corpos receptores de classe II (250 mg/L).

Foi estabelecido o procedimento experimental para alcançar bons rendimentos de remoção de sulfato por precipitação de etringita, em sistema contínuo, quando se estuda uma solução sintética de sulfato (1.654 mg/L), ou seja, tempo de residência de 30 minutos, agitação do sistema próxima de $360 \mathrm{~min}^{-1}$ e razão estequiométrica entre as espécies química envolvidas na precipitação. Nessas condições, as concentrações residuais estão próximas a 250 mg/L e o controle do pH não afeta a remoção de sulfato.

\section{Agradecimentos}

Os autores agradecem à FINEP, ao CNPq e à FAPEMIG, pelo financiamento. Ao CNPq, pelas bolsas PQ de V. A. Leão e R. M. F Lima. 


\section{Referências}

ÁLVAREZ-AYUSO, E.; NUGTEREN, H. W. Synthesis of ettringite: a way to deal with the acid wastewaters of aluminium anodising industry. Water Research, v.39, n.1, p.65-72, 2005.

CADORIN, L.M. Desenvolvimento de técnicas de remoção de íons sulfato de efluentes ácidos de minas por precipitação química e flotação por ar dissolvido. 119f. Dissertação (Mestrado em Engenharia). Programa de Pós-Graduação em Engenharia Minas, Metalúrgica e de Materiais da UFRGS, Porto Alegre, 2008

CODY, A.M.; LEE, H.; CODY, R.D., et al. The effects of chemical environment on the nucleation, growth, and stability of ettringite $\left[\mathrm{Ca}_{3} \mathrm{Al}(\mathrm{OH})_{6}\right]_{2}(\mathrm{SO} 4)_{3} \cdot 26 \mathrm{H}_{2} \mathrm{O}$. Cement and Concrete Research, v.34, n.5, p. 869-881, 2004.

DUTRIZAC, J.E. The effect of seeding on the rate of precipitation of ammonium jarosite and sodium jarosite. Hydrometallurgy, v. 42, n. 3, p. 293-312, 1996

FERREIRA, B.C.S. Precipitação Química de Sulfato Contido em Efluentes Líquidos Gerados no Setor Mínero/Metalúrgico. 159f. Dissertação (Mestrado em Engenharia Ambiental). Programa de Pós-Graduação em Engenharia Ambiental da UFOP, Ouro Preto, MG, Brasil, 2010.

GELDENHUYS, A.J.; MAREE, J.P.; DE BEER, M.P.H. An integrated limestone/lime process for partial sulphate removal. The Journal of The South African Institute of Mining and Metallurgy, v. 103, n. 6, p. 345-354, 2003.

INTERNATIONAL NETWORK FOR ACID PREVENTION (INAP) [Internet]. Treatment of sulphate in mine effluentes. International network for acid prevention. 129 p. 2003. Disponível em: <http://www.inap.com.au/ public_downloads/Research_Projects/Treatment_of_Sulphate_in_Mine_ Effluents_-_Lorax_Report.pdf >. Acesso em: jan 2012.

LAUBSCHER, C.; PETERSEN, F.; SMIT, J. Treatment of acid mine drainage through chemical precipitation. In: INTERNATIONAL MINERAL PROCESSING CONGRESS. Cape Town, SA: South African Institute of Mining and Metalllurgy, 2003. p. 1814-1820.

LIMPO, J.L. et al. Cinética y mecanismo de la precipitacion del hierro como jarosita. Revista de Metalurgia - Centro Nacional de Investigaciones Metalúrgicas, v. 12, p. 123-125, 1976.

MOHAN, D.; CHANDER, S. Removal and recovery of metal ions from acid mine drainage using lignite - A low cost sorbent. Journal of Hazardous Materials, v. 137, n. 3, p. 1545-1553, 2006.

MYNENI, S.C.B.; TRAINA, S.J.; LOGAN, T.J. Ettringite solubility and geochemistry of the $\mathrm{Ca}(\mathrm{OH})_{2}-\mathrm{Al}_{2}\left(\mathrm{SO}_{4}\right)_{3}-\mathrm{H}_{2} \mathrm{O}$ system at $1 \mathrm{~atm}$ pressure and 298 K. Chemical Geology, v. 148, n. 1-2, p. 1-19, 1998.

RAMAN, R. et al. Alkaline decomposition-cyanidation kinetics of argentian natrojarosite. Hydrometallurgy, v. 49, p. 323-336, 1998.

SILVA, A.J. et al. Sulphate removal from industrial wastewater using a packedbed anaerobic reactor. Process Biochemistry, v. 37, n. 9, p. 927-935, 2002.

TAVARES, L.Y. Precipitação de jarosita em soluções de sulfato de manganês. 135f. Dissertação (Mestrado em Engenharia de Materiais e de Processos Químicos e Metalúrgicos). Programa de Pós-Graduação em Engenharia de Materiais e de Processos Químicos e Metalúrgicos da PUC-Rio, Rio de Janeiro, 1986.

TORO, L.; PAPONETTI, B.; CANTALINI, C. Precipitate formation in the oxidation of ferrous ions in the presence of Thiobacillus ferrooxidans. Hydrometallurgy. v. 20, p. 1-9, 1988.

US ENVIRONMENTAL PROTECTION AGENCY (USEPA) [Internet]. 2009 Edition of the Drinking Water Standards and Health Advisories Tables. U.S. Environmental Protection Agency. Washington, DC, 18p. 2009. (EPA/600/ R-95/068). Disponível em: <http://www.epa.gov/waterscience/criteria/ drinking/dwstandards2009.pdf $>$.

VIEIRA, A.C. Síntese, Caracterização e Aplicação de Hidróxidos Duplos Lamelares. 127f. Dissertação (Mestrado em Engenharia Ambiental). Programa de Pós-Graduação em Engenharia Ambiental da UFOP, Ouro Preto, MG, Brasil, 2009.

WORLD HEALTH ORGANIZATION (WHO) [Internet]. Guidelines for drinking-water quality. Genebra, 2008. Disponível em: < http://www.who. int/water_sanitation_health/dwq/fulltext.pdf > . Acesso em: jan 2012. 